\title{
Fuzzy Synthetic Evaluation Based Method to Evaluate Online Courses
}

\author{
Junyan Zhao, Jianbao Gao \\ Network Education College, East China University of Science and Technology, Shanghai 200237, \\ China \\ zhaojunyan@ecustmde.com, jianbaogao@ecustmde.com
}

\begin{abstract}
Keywords: Fuzzy Synthetic Evaluation; online course evaluation; online education
\end{abstract}
\begin{abstract}
In online education, course evaluation is a key element to improve the teaching quality, and the education managers have to attach importance to evaluate the course. In this paper, we propose a Fuzzy Synthetic Evaluation based method to evaluate the course, the different factors are considered in the evaluation process. On the basis of principles of online course evaluation, Fuzzy Synthetic Evaluation is used to evaluate the course, which can evaluate the online course from different aspects, thus providing teachers with clear and actionable feedback to enhance their practice.
\end{abstract}

\section{Introduction}

Online education is learner-centered system, the teacher can provide the course materials, such as curriculum plans, courseware and related information on the learning Website, the students can get those network courses and related services via computer and network [1]. In the learning process, the students can communicate with their teachers and students by using E-mail, discussion boards and chat rooms, the teachers can provide the guidance and help. The advantage of online education is [2]: (1) The student can learn the related courses at any time and place. (2) It is more effective for some special learners, such as the distance learner, the learner with physical disabilities, learners have the talent in certain areas as well as those who love contemplative and good at writing to express their idea. (3) The teaching ways can be more personalized and flexible.

Online education course, it is the course used for the network education [3]. First of all, it is the course, secondly, we emphasize that it must have the network characteristics. Therefore, the online education is teaching activities that use to realize the teaching content of course and its enforcement. It consists of two parts: (1) the teaching content is organized by using a certain teaching objectives and teaching strategies. (2) The network teaching supporting environment, network teaching environment is the software tools using to support online teaching, teaching resources, and the teaching activity running on the network teaching platform. At present, the form of online education is flourishing and different. The quality of online course is a key part that restricts the whole network education, how to evaluate the online education course is a hot topic in the education field [4, 5]. And how to use the new teaching ideas and new educational perspective to construct the new training objectives that meet the actual requirement, system integrity and reasonable structure of online course evaluation system has a positive meaning for improving the network teaching management and the teaching quality. The evaluation of online course refers that the development of scientific criteria and use a series of feasible controlled technologies, methods and means to measure and evaluate the teaching process based on the teaching objectives.

The evaluation of online course can timely feedback the related information in order to regulate the teaching activities between teacher and student, thus ensuring the effectiveness of teaching [6]. For the students, the evaluation of online course mainly enhances the learning autonomy through the self-evaluation feedback and self-understanding. For the teachers, it can help find the strengths and weaknesses in the teaching process by timely getting the information about the various aspects of the network teaching in the enforcement process, and the teacher can adjust and improve teaching based on the feedback. 
In order to satisfy these requirements, the evaluation of online course must be adequately funded and staffed, and fully developed and validated. This paper proposes a Fuzzy Synthetic Evaluation based method to evaluate online course. Below summarizes our main contributions: We evaluate the quality of online course from various aspects related to learning, and involve various objects associated with the learners. Then we use the Fuzzy Synthetic Evaluation, which can evaluate the teacher ability from different aspects, thus providing teachers with clear and actionable feedback to enhance their practice.

The rest of this paper is organized as follows. Section 2 presents the evaluation index of online education courses, and Section 3 describes the Fuzzy Synthetic Evaluation and its construction steps. Next, we give the case study to illustrate the evaluation process. Finally, Section VII concludes.

\section{Evaluation Index of Online Education Courses}

This paper divides the teaching objects into two levels by decomposing the goals and analyzing the main factors and their properties of online education courses, thereby forming the index system. The first index is divided into four indicators: teaching, scientific, technology and teaching activities, which is shown in the Table 1. The second level will get based on the first level.

Table 1 Course Evaluation Index

\begin{tabular}{|c|c|c|c|c|c|c|}
\hline \multirow[t]{2}{*}{ Primary index } & \multirow[t]{2}{*}{ Secondary index } & \multicolumn{5}{|c|}{ Evaluation } \\
\hline & & Excellent & Good & Ordinary & Poor & Very poor \\
\hline \multirow{4}{*}{ Technology } & Innovation & 0.5 & 0.15 & 0.2 & 0.15 & 0 \\
\hline & Learning support tools & 0.2 & 0.6 & 0.1 & 0.1 & $\mathbf{0}$ \\
\hline & Teaching support tools & 0.4 & 0.4 & 0.1 & 0 & 0.1 \\
\hline & Course management & 0.1 & 0.3 & 0.5 & 0.05 & 0.05 \\
\hline \multirow{5}{*}{ Teaching } & Purpose & 0.3 & 0.5 & 0.15 & 0.05 & 0 \\
\hline & Structure & 0.4 & 0.2 & 0.2 & 0.1 & 0.1 \\
\hline & Content & 0.4 & 0.4 & 0.1 & 0.1 & 0 \\
\hline & Means & 0.1 & 0.3 & 0.3 & 0.2 & 0.1 \\
\hline & Resource & 0.1 & 0.2 & 0.5 & 0.2 & 0.1 \\
\hline \multirow{4}{*}{ Scientific } & Political thought & 0.1 & 0.3 & 0.3 & 0.2 & 0.1 \\
\hline & Courseware design & 0.2 & 0.3 & 0.3 & 0.1 & 0.1 \\
\hline & Innovation & 0.2 & 0.4 & 0.2 & 0.15 & 0.05 \\
\hline & Information carrier & 0.1 & 0.3 & 0.4 & 0.1 & 0.1 \\
\hline \multirow{4}{*}{ Teaching activity } & Teaching interactivity & 0.1 & 0.3 & 0.4 & 0.1 & 0.1 \\
\hline & Student interactivity & 0.3 & 0.4 & 0.2 & 0.1 & 0 \\
\hline & Training & 0.2 & 0.3 & 0.4 & 0.1 & 0 \\
\hline & Others & 0.4 & 0.3 & 0.2 & 0.1 & 0 \\
\hline
\end{tabular}




\section{Fuzzy Synthetic Evaluation and Its Construction Steps}

\section{Fuzzy Synthetic Evaluation}

Synthetic evaluation is a multi-factor decision-making method by giving a comprehensive evaluation to object, and it is the core problem of resource management, complex system optimization and so on [7]. Since the connotation and extension of the evaluation factors are often not precise and they correlate with each other, fuzzy synthetic evaluation is a common used evaluation method. Constructing a fuzzy synthetic evaluation model which can deal with the interaction is concerned widely in academic fields [8]. Many scholars gave many discussions under different backgrounds and also obtained many important research results.

The methods of evaluating online course quality are various, and mainly involves the fuzzy mathematical theory, grey system theory and matterelement analysis theory, etc. The problems discussed in this paper actually belongs to the fuzzy online course evaluation, in the fuzzy synthetic evaluation of atmosphere quality, it need to determine the main factors which influence the online course quality, the factor set, evaluation set, Fuzzy Membership Function, and then through calculating the weights and memberships of various factors, we can get the synthetic membership, and ascertain quality rank.

\section{The construction steps of Fuzzy Synthetic Evaluation}

The weight design is an important content in the process of fuzzy synthetic evaluation and make important influence to the evaluation results. The Fuzzy synthetic valuation Methods usually determine the weights of each factor by calculating the over standard ratio, that is according to the degree of exceeding standard which the monitoring value of each evaluation index of certain object which need to be evaluated relative to the Standard average value of atmosphere quality and then take the results of normalized calculation as the factor weight. The evaluation of online course may involve many indexes, so we need consider many factors. If we still use the fuzzy comprehensive evaluation with one level, there must face two problems. (1) It has too many factors, which are difficult to determine the distribution of weight. (2) Because it needs to satisfy the normalization condition, the weight of each factor is small even if the distribution of weight is determinate. Therefore, the evaluation of online education course can use a multi-level fuzzy comprehensive evaluation. In this paper, we use the fuzzy comprehensive evaluation with two levels. If we want to divide more level based on the actual requirement, we can use the similar method to do it.

We will give the steps for establishing the secondary fuzzy comprehensive evaluation model.

Step 1: Analyzing the association between the set of primary factor $U=(U 1, U 2, . ., U n)$ and the set of secondary factor. Where $\mathrm{Ui}=\{$ ui1, ui2, ..., uik $\}$, and meet the condition $i \neq j, \mathrm{Ui} \cap U \mathrm{j}=\varnothing$.

Step 2: For each set of factor Ui, we will make a comprehensive evaluation respectively. Let $\mathrm{V}=\{\mathrm{v} 1, \mathrm{v} 2, \ldots \mathrm{vm}\}$ be the set of evaluation, the weight of each factor in $\mathrm{Ui}$ is: $\mathrm{Ai}=($ ai1,ai2,..,aik).

The evaluation matrix of single factor $\mathrm{Ri}=(\mathrm{rjf}) \mathrm{kXm}$, rjf is the score of sub-factor uij in the evaluation vf.

Based on this, we can obtain an evaluation vector: $\mathrm{Bi}=\mathrm{Ai} * \mathrm{Ri}=(\mathrm{bi} 1, \mathrm{bi} 2, \ldots, \mathrm{bim}), \mathrm{i}=1,2, \ldots, \mathrm{n}$.

Step 3: Computing the secondary evaluation vector B:

According to the primary evaluation vector, we can get the evaluation matrix of factor $\mathrm{U}=(\mathrm{U} 1, \mathrm{U} 2, . ., \mathrm{Un})$ :

$$
\mathrm{R}=\left[\begin{array}{c}
B_{1} \\
B_{2} \\
\ldots \\
B_{n}
\end{array}\right]=\left[\begin{array}{cccc}
b_{11} & b_{11} & \ldots & b_{1 m} \\
b_{21} & b_{22} & \ldots & b_{2 m} \\
\cdots & \\
b_{n 1} & b_{n 2} & \ldots & b_{n m}
\end{array}\right]
$$

Each $U$ i is viewed as part of the $U$, which reflects a property of $U$, we can give the distribution of weight $\mathrm{A} i=(\mathrm{a} 1, \mathrm{a} 2, . ., \mathrm{an})$ based on its importance, thereby getting the secondary evaluation vector:

$\mathrm{B}=\mathrm{A} * \mathrm{R}=(\mathrm{b} 1, \mathrm{~b} 2, \ldots, \mathrm{bn}), \mathrm{i}=1,2, \ldots, \mathrm{n}$ 
If each set of sub-factor Ui contains more elements, we can divide Ui again, then we can get the three evaluation model, even four, five models.

\section{Case Study}

In this section, we will use the proposed method to evaluate the course which is shown in Table 1.

Step 1: Determining the weight of each index, which can get by combining some historical data and the opinions of experts: the experts can set the weight of each index, the weight of primary index: $\mathrm{A}=(0.2,0.4,0.1,0.3)$, the weight of secondary index is: $\mathrm{A} 1=(0.2,0.3,0.3,0.2), \mathrm{A} 2=(0.1,0.1,0.3$, $0.3,0.2)$, A3 = (0.1, 0.5, 0.2, 0.2), A4 = (0.3, 0.3, 0.2, 0.2).

Step 2: Doing the primary fuzzy comprehensive evaluation for each set of sub-factor.

According to Table 1, we can get the score R1, R2, R3, R4. Ri is the evaluation of factor Ui. For example, $R 1=\left[\begin{array}{ccccc}0.5 & 0.15 & 0.2 & 0.15 & 0 \\ 0.2 & 0.6 & 0.1 & 0.1 & 0 \\ 0.4 & 0.4 & 0.1 & 0 & 0.1 \\ 0.1 & 0.3 & 0.5 & 0.05 & 0.05\end{array}\right]$,

Then $\mathrm{B} 1=\mathrm{A} 1 * \mathrm{R} 1=(0.3,0.39,0.2,0.7,0.04)$, we can do the primary comprehensive evaluation for the rest of three factors, which are:

$B 2=A 2 * R 2=(0.24, \quad 0.32, \quad 0.255, \quad 0.145, \quad 0.06) . \quad B 3=A 3 * R 3=(0.17,0.32,0.3,0.12,0.09)$. $B 4=A 4 * R 4=(0.24,0.33,0.3,0.1,0.03)$

Step 3: The secondary comprehensive evaluation is:

The secondary evaluation matrix:

$$
R=\left[\begin{array}{ccccc}
0.3 & 0.39 & 0.2 & 0.7 & 0.04 \\
0.24 & 0.32 & 0.255 & 0.145 & 0.06 \\
0.17 & 0.32 & 0.3 & 0.12 & 0.09 \\
0.24 & 0.33 & 0.3 & 0.1 & 0.03
\end{array}\right]
$$

$B=A^{*} R=(0.245,0.337,0.262,0.24,0.05)$.

According to the principle of maximum degree of membership, we can consider that the evaluation of course can meet the requirement. We can assess the other courses by using the same method.

It should be noted that, when the sum of the results of several evaluation is not equal to"1" in the final evaluation, we can directly use the evaluation results, or we can do the normalization process for the evaluation result, and then use the evaluation result.

\section{Summary}

In this paper, we proposed a Fuzzy Synthetic Evaluation based method to evaluate the course in network education. This approach is based on Fuzzy Synthetic Evaluation, which allows to take into account different factors in the evaluation process. Fuzzy Synthetic Evaluation is used to evaluate the online course, thus extracting benefits from all the combined criterions, and hence, achieve the desired goal in a better way. We can use this method to evaluate the course, which has the merits of rich expressivity, while providing the teachers with clear and actionable feedback to enhance their practice

\section{References}

[1] Y. Sun, D. Chen, W. Jiao and G. Huang. An nnline education approach using Web operation record and replay techniques. Processing of the 38th Annual International Computers, Software and Applications Conference (COMPSAC 2014). Washington: IEEE Computer Society Press, 2014:456-465. 
[2] X. Yu, P. Li, X. Sun. Researching on network education in institutions of higher learning. The 2009 International Conference on Information Management, Innovation Management and Industrial Engineering. IEEE Computer Society, Washington, DC, USA, 2009: 466-469.

[3] A. Loya, A. Gopal, I. Shukla, P. Jermann and R. Tormey. Conscientious behaviour, flexibility and learning in massive open On-Line courses. Procedia - Social and Behavioral Sciences. Vol. 191 (2015), p. 519-525.

[4] A. Margaryan and M. Bianco and A. Littlejohn. Instructional quality of Massive Open Online Courses. Computers \& Education. Vol. 80 (2015), p. 77-83.

[5] G. Gorghiu and L. M. Gorghiu. A romanian student profile for a european On-line Course-The “Designing TEL Course" experience. Procedia - Social and Behavioral Sciences. Vol. 116(2014), p. 138-42.

[6] S. Hubackova. Effectiveness and Evaluation of On-line Courses. Procedia - Social and Behavioral Sciences. Vol. 143(2014), p. 139-142.

[7] C.Mi, X.Zhang, S.Li, J. Yang, D. Zhu and Y.Yang. Assessment of environment lodging stress for maize using fuzzy synthetic evaluation. Mathematical and Computer Modelling. Vol. 54(2011), p. 1053-1060.

[8] M. Huang, W.H. Ip, H.Yang, X. Wang and H. C.W. Lau. Developing a risk assessment model for PPP projects in China - A fuzzy synthetic evaluation approach. Automation in Construction. Vol. 116(2008), p. 104-114. 